\title{
Compliance with the WHO strategy of test, treat and track for malaria control at Bosomtwi District in Ghana
}

\author{
Gideon Oteng, Ernest Kenu, Delia A. Bandoh, Priscillia Nortey, Edwin A. Afari \\ Ghana Med J 2020; 54(2) supplement: 40-44 DOI: http://dx.doi.org/10.4314/gmj.v54i2s.7 \\ ${ }^{1}$ Ghana Field Epidemiology and Laboratory Training Program, Department of Epidemiology, School of Public \\ Health, College of Health Sciences, University of Ghana Legon, Accra, Ghana
}

Corresponding author: Ernest Kenu
Conflict of interest: None declared

E-mail: ernest_kenu@yahoo.com

\section{SUMMARY}

Background: We reviewed malaria morbidity data to assess compliance to malaria T3 strategy in Bosomtwi District, Ashanti Region, Ghana.

Design: The study was descriptive secondary data analysis

Setting: Bosomtwi District

Data source: District Health Information Management Systems (DHIMS2)

Main outcome: Proportion of recorded cases tested, proportion of tested cases treated and proportion of cases tracked Results: Data for suspected and tested malaria cases was complete for only 3 years (2014-2016). Malaria testing reduced from $84.4 \%$ in 2015 to $76.8 \%$ in 2016 (national average $77.3 \%$; regional average $70 \%$ ). The proportion of untested but treated malaria cases declined from $46.3 \%$ in 2015 to $4.9 \%$ in 2016 . Proportion of confirmed malaria cases put on antimalarial drugs was highest in 2016 at $63.9 \%$. Pramso sub-district although home to largest facility in the district, under prescribed antimalarial drugs. Reports generated on malaria showed information on only confirmed suspected cases, under five, and above five malaria mortalities. The district did not determine their malaria thresholds. Conclusion: The malaria-testing rate in the Bosomtwi District is higher than the regional average and close to the national average. About a third of confirmed malaria cases missed getting appropriate antimalarial drugs. Limited analysis on malaria data reduced the information required to inform policy.

Keywords: Malaria, Test, Treat and Track (T3), DHIMS2, Bosomtwi, Ghana. Funding: Author GO was fully sponsored by President's Malaria Initiative (PMI)-CDC CoAg 6NU2GGH001876

\section{INTRODUCTION}

Although malaria is treatable and preventable, it remains a public health problem. According to WHO, about half of the world's population were at risk of malaria in 2017 and most of these cases (92\%) and deaths (93\%) occurred in Sub-Saharan Africa. Children under 5 years in areas of high malaria transmission are particularly susceptible, with $70 \%$ of all malaria deaths occurring in this age group. ${ }^{1}$

Until recent times, fever in Sub-Sahara Africa was assumed to be caused by malaria and thus treated presumptively. ${ }^{2}$ Some factors that may have contributed to this practice were: the high burden of malaria at that time and the need to reduce malaria-attributable mortality, inadequate human resource capacity, and lack of requisite laboratory equipment for malaria diagnosis in peripheral health facilities in Sub-Saharan Africa. ${ }^{3}$
The result of this was over-diagnosis of malaria and hence over-prescription of antimalarial drugs which led to increasing parasite resistance. ${ }^{4}$

Malaria RDTs were therefore developed in the early 1990's to help overcome the shortcomings of other laboratory diagnostic techniques..$^{5-7}$ In addition to preventive methods such as chemoprophylaxis and vector control (insecticide treated mosquito nets and indoor residual spraying), the WHO Global Malaria Program launched the Test, Treat, Track (T3) strategy in 2012 to support malaria-endemic countries to increase diagnostic testing, antimalarial treatment coverage, and strengthen malaria surveillance systems. ${ }^{8}$ Not testing for malaria and subsequent treatment with ACTs is likely to result in the possibility of misdiagnosis especially in children, as well as the inappropriate use of highly expensive ACTs. These interventions notwithstanding, the burden of malaria remains high at 219 million cases and 435,000 deaths in $2017 .^{1}$ 
Malaria is endemic in Ghana. In 2016, about 10.4 million suspected malaria cases were recorded at outpatient departments (OPD) in the country's health facilities. Only about $43.4 \%$ were tested and confirmed. ${ }^{9}$ About $24.8 \%$ of all admissions and $4.2 \%$ of all deaths were attributed to malaria. ${ }^{10}$ Malaria places a heavy burden on health and productivity, hence affecting economic development in Ghana. In 2014, businesses in Ghana lost about US\$6.58 million to due to malaria morbidity, $90 \%$ of which were as a result of direct costs, and a loss of about 3,913 workdays. ${ }^{11}$

To ensure efficient use of resources to treat malaria and monitor the progress made in the control effort, Ghana subscribed to the T3 strategy in 2013 to ensure all suspected malaria cases are tested, confirmed cases treated with appropriate ACTs and then these cases effectively tracked to help guide policies and operational decisions. This was done by updating the 2009 malaria case management guidelines. ${ }^{12}$ Strictly adhering to this T3 initiative will boost efforts towards eliminating malaria. ${ }^{13}$

Since implementation of the T3 strategy, the proportion of OPD malaria cases tested for malaria has increased from $48 \%$ in 2013 to $77.3 \%$ in $2016 .^{10,14}$ Routine collection and analysis of malaria data is very useful for making informed decisions towards allocation of resources to improve the disease burden and hence the need for a national database for routine collection of data. The District Health Information Management System (DHIMS2) is a web-based database for routine collection of morbidity and mortality health data in Ghana.

DHIMS2 helps in tracking malaria cases from the district to national level. Malaria contributed to about $48.2 \%$ of OPD attendance in 2016 in the Bosomtwi District. ${ }^{15}$ Although malaria morbidity data is routinely collected, limited analysis is done on them to determine whether the T3 strategy is being adhered to in the Bosomtwi District. We therefore reviewed the malaria morbidity data to assess the compliance to malaria T3 (test, treat and track) strategy in the district.

\section{METHODS}

\section{Study site}

The Bosomtwi District is located in the central part of the Ashanti Region, with a population of 93,910, representing $2.0 \%$ of the region's total population and made up of 66 communities. ${ }^{16}$ The Bosomtwi District is one of the 216-second level administration units (districts) in Ghana and one of 30 districts in the Ashanti Region. The district is divided into four sub-districts namely; Amakom, Jachie, Kuntanase and Pramso sub-districts and has eighteen (18) public and private health institutions.

\section{Study design}

In July 2017, we conducted a descriptive secondary data analysis of DHIMS2 malaria morbidity data from 2012 2016 to assess T3 compliance in the Bosomtwi District.

\section{Data Collection}

A structured questionnaire was used to interview the District Disease Control Officer and the District Health Information Officer on how District Health Information Management System (DHIMS2) works and on data collection and entry. We abstracted aggregated malaria morbidity and mortality data including: malaria cases suspected, malaria cases tested, malaria cases confirmed, malaria cases put on ACTs, malaria cases not tested but treated as malaria, age and sub-district that had been generated by the Bosomtwi District for 2012-2016 from DHMIS2.

The first $\mathrm{T}$ (Test) is to ensure that all suspected malaria cases are tested before treatment is started and to assess this, we used the proportion of suspected malaria cases that were actually referred for testing by either microscopy or RDT. The second T (Treat) is to ensure that all confirmed malaria cases receive appropriate antimalarial medication, and this was assessed by finding the proportion of confirmed malaria cases that received ACTs. The last $\mathrm{T}$ (track) is to ensure that every malaria case is tracked in a surveillance system to ensure effective malaria control. Reports generated on malaria by the district were reviewed to assess the tracking aspect of the T3 initiative. Details that were looked for included: availability of malaria thresholds, charts showing monthly malaria cases and deaths, as well as whether analysis was done according to sub-district or health facility.

\section{Data Analysis}

Abstracted data was cleaned in Microsoft Excel 2013 where descriptive analysis was done. Relative frequencies for the selected variables were generated and presented in tables and graphs.

\section{Ethical consideration}

The Director of the Diseases Surveillance Department of the Ghana Health Service granted approval for the access and use of the data for this review. Permission was also officially granted by the Regional Director of Health Services for the use of the data. All identifiers were removed from the data. Data held on computers were encrypted with a password that was made available only on a need to know basis.

\section{RESULTS}


Suspected malaria case testing rate in the district increased in 2015 but reduced in 2016. However, children under five, and pregnant women showed no decline in testing rates (Table 1).

Table 1 Testing rate of malaria in the Bosomtwi District, $2014-2016$.

\begin{tabular}{|l|l|l|l|}
\hline \multicolumn{2}{|l|}{ Year } & & \\
\cline { 2 - 4 } & 2014 & 2015 & 2016 \\
\hline All cases & & 28786 & 51990 \\
\hline $\begin{array}{l}\text { Suspected no. of malaria } \\
\text { cases }\end{array}$ & 31798 & 24300 & 39904 \\
\hline $\begin{array}{l}\text { No of suspected cases } \\
\text { tested (\%) }\end{array}$ & $\begin{array}{l}17413 \\
(54.8 \%)\end{array}$ & $\begin{array}{l}(84.4 \%) \\
(76.8 \%)\end{array}$ \\
\hline $\begin{array}{l}\text { Children less than 5 years } \\
\text { Suspected no. of malaria } \\
\text { cases }\end{array}$ & 9234 & 7671 & 10317 \\
\hline $\begin{array}{l}\text { No of suspected cases } \\
\text { tested (\%) }\end{array}$ & $\begin{array}{l}5541 \\
(60.0 \%)\end{array}$ & $\begin{array}{l}6218 \\
(80.2 \%)\end{array}$ & $\begin{array}{l}9190 \\
(89.1 \%)\end{array}$ \\
\hline \begin{tabular}{l} 
Pregnant women \\
\hline $\begin{array}{l}\text { Suspected no. of malaria } \\
\text { cases }\end{array}$
\end{tabular} & 289 & 261 & 594 \\
\hline $\begin{array}{l}\text { No of suspected cases } \\
\text { tested (\%) }\end{array}$ & $\begin{array}{l}285 \\
(98.6 \%)\end{array}$ & $\begin{array}{l}258 \\
(98.8 \%)\end{array}$ & $\begin{array}{l}594 \\
(100 \%)\end{array}$ \\
\hline
\end{tabular}

The proportion of untested malaria cases that were treated declined from $46.3 \%$ in 2015 to $4.9 \%$ in 2016 . The proportion of confirmed malaria cases put on ACTs in the district increased in 2016 to about 64\% from $44 \%$ in 2014 and 2015. This proportion had an inverse relation with suspected malaria cases not tested but treated as malaria. Kuntanase was the only sub-district to maintain decreasing proportion of malaria cases not tested but treated as malaria.

\section{Tracking of malaria cases}

The district did not determine malaria surveillance thresholds. In addition, cases and deaths were recorded, but there were no monthly monitoring charts to show the trend of cases and deaths. Malaria data analysis was also not done by health facilities while those that were done at sub-district levels were limited in scope and depth.

\section{DISCUSSION}

This study assessed compliance to WHO Test, Treat and Track (T3) initiative for malaria control in the Bosomtwi District. The T3 initiative was mainly to ensure accurate profiling of the malaria burden in the country, and to reduce pressure on antimalarial drugs by ensuring that only confirmed cases are given treatment. Strictly adhering to this $\mathrm{T} 3$ initiative will facilitate progress towards malaria elimination. ${ }^{13}$

The overall testing rate of malaria in the district declined from $84.4 \%$ in 2015 to $76.8 \%$ in 2016 . Testing which is the first aspect of the T3 initiative is important because it helps in ensuring rational use of antimalarial drugs and managing other febrile illnesses that would have been misdiagnosed and managed as malaria. Although the test- ing rate of suspected malaria in the Bosomtwi District declined in 2016, it was still close to the national average $(77.3 \%)$ and higher than the regional average of about $70 \%,{ }^{9,10}$ an indication of ongoing efforts to improve malaria management and control in the district.

However, our finding is still short of the WHO target of $100 \%$. These improvements in testing rates for suspected malaria cases may have been enhanced by availability of test kits for malaria. Testing rates for children under five was as high as $89.1 \%$ and those for pregnant women in the district were above $90 \%$. This finding can be attributed to the special interest in these two groups, as they are more vulnerable to malaria.

The proportion of unconfirmed (not tested) cases treated for malaria in the district reduced to $4.9 \%$ in 2016. Presumptive treatment for malaria is on the decline due to increasing adherence to the treatment recommendations of T3 initiative. It is therefore expected that suspected malaria cases that were not tested but treated as malaria would reduce further over time. Presumptive treatment for malaria is likely to affect the proportion of confirmed malaria cases that would receive ACTs, possibly due to drug shortages that would arise from increased demand. The inverse relation between confirmed malaria cases put on ACTs and cases not tested but treated as malaria showed this. This improved performance is probably influenced by the cooperation of prescribers in adhering to the treating aspect of the T3 initiative, because they are unlikely to treat for malaria when test results are negative. Prudent use of antimalarial can help prevent complications associated with malaria as well as help prevent antimalarial resistance of the Plasmodium parasites. ${ }^{19}$

The Bosomtwi district was able to put only about $64 \%$ of confirmed malaria on appropriate antimalarial drugs. This proportion of confirmed malaria receiving treatment in 2016 however means that, about four out of ten people did not receive treatment. This could lead to fatalities or creation of asymptomatic malaria reservoirs that could undermine the country's goal of achieving elimination.

Similar findings were observed in a study in the Kintampo North and South districts where compliance with ACT guidelines was about $66 \%{ }^{20}$, although other studies also in Ghana found all or almost all malaria positive cases have been put on ACTs. ${ }^{13,21}$ This high ACT compliance in the last two studies could have been due to the study participants being children under five and their vulnerability to malaria.

There was limited surveillance on malaria in the district. Limited surveillance on malaria data reduces the information that can be used for policy changes. The lack of thresholds for malaria and monthly monitoring charts for 
cases and deaths, as well as the limited analysis on malaria data is undermining the Tracking aspect of the T3 initiative. Epidemic thresholds for malaria were not calculated though they help in the identification potential outbreaks and communities more at risk for targeted interventions can be carried out. The District Health Information and Disease Control Officers can help improve malaria surveillance by ensuring detailed analysis is done on malaria data generated. Tracking malaria cases effectively in the national surveillance system for analysis would help guide policy development. ${ }^{17}$ This would help ensure identification of hotspots for targeted interventions in the district, as well as the region, which would contribute to the overall national efforts to eliminate malaria. Improvements made on this last aspect of the T3 initiative in the district would enable measurement of the impact of the interventions made in malaria control in the country's quest for elimination. Concerted efforts need to be made by the District Health Directorate to ensure that all health facilities strictly adhere to the $\mathrm{T} 3$ initiative of malaria management. Again organising regular training on data entry into DHIMS2 for data capturers could also help improve data quality.

\section{Limitations}

The study used secondary data reported through routine services; therefore, there were data quality issues which limited the analysis that could be done. This was reduced by verifying data extracted with district health officials in charge of the district's data.

\section{CONCLUSION}

The malaria testing rate in the Bosomtwi District is high. However, improvements need to be made on the treating and tracking components of the T3 initiative. The proportion of confirmed malaria cases not given antimalarial treatment is an indication for improvements in the treatment aspect of the T3 initiative and the quality of data entered into DHIMS2.

\section{REFERENCES}

1. World Health Organization. Malaria. 2018. Retrieved: https://www.who.int/en/news-room/factsheets/detail/malaria.

2. Boyce MR, O'Meara WP. Use of malaria RDTs in various health contexts across sub-Saharan Africa: a systematic review. BMC Public Health. 2017;17(1):1-15.

3. Masanja MI, Mcmorrow M, Kahigwa E, Kachur SP, Mcelroy PD. Health Workers ' Use of Malaria Rapid Diagnostic Tests ( RDTs ) to Guide Clinical Decision Making in Rural Dispensaries, Tanzania. Am J Trop Med Hyg. 2010;83(6):1238-1241.

4. Reyburn H, Mbatia R, Drakeley C, Carneiro I, Mwakasungula E, Mwerinde O, et al. Overdiagnosis of malaria in patients with severe febrile illness in Tanzania: A prospective study. $\mathrm{Br}$ Med $J$. 2004;329(7476):1212-1215.

5. Moody A. Rapid Diagnostic Tests for Malaria Parasites. Clin Microbiol Rev. 2002;15(1):66-78.

6. Uzochukwu BSC, Onwujekwe E, Ezuma NN, Ezeoke OP, Ajuba MO, Sibeudu FT. Improving rational treatment of malaria: Perceptions and influence of RDTs on prescribing behaviour of health workers in Southeast Nigeria. PLoS One. 2011;6(1):1-7.

7. Laurent A, Schellenberg J, Shirima K, Ketende SC, Alonso PL, Mshinda H, et al. Performance of HRP2 based rapid diagnostic test for malaria and its variation with age in an area of intense malaria transmission in southern Tanzania. Malar $J$. 2010;9(1):294.

8. World Health Organization. Scaling up Diagnostic Testing, Treatment and Surveillance for Malaria. 2012. Geneva. Retrieved: https://www.who.int/malaria/publications/atoz/test_treat_track_brochure.pdf.

9. National Malaria Control Program. Malaria Annual Bulletin. 2017 retrieved: http://www.ghanahealthservice.org/downloads/2016 -Annual_Bulletin.pdf.

10. Ghana Health Service. Ghana Health Service 2016 Annual Report. 2017 retrieved: doi:10.1136/bjo.2010.193169.

11. Nonvignon J, Aryeetey GC, Malm KL, Agyemang SA, Aubyn VNA, Peprah NY, et al. Economic burden of malaria on businesses in Ghana: a case for private sector investment in malaria control. Malar J. 2016;15(454). doi:10.1186/s12936-016-1506-0.

12. Ministry of Health, Ghana Health Service, Global Fund, WHO, Guilin Pharma, Malaria Care. Guidelines for Case Management of Malaria in Ghana. 3rd Edition. 2014. Retrieved: http://www.ghanahealthservice.org/downloads/GUIDELINE FOR CASE MANAGEMENT .pdf.

13. Ghana Health Service. Ghana Health Service 2014 Annual Report. 2015 retrieved: http://www.ghanahealthservice.org/downloads/Ghana_Health_Service_2014_Annual_Report.pdf.

14. GHS. Bosomtwi District Health Directorate 2016 annual report. GHS, Kumasi. 2017.

15. Ghana Statistical Service. 2010 Population \& Housing Census. District Analytical Report-Bosomtwe district. GSS. Accra. 2014.

16. Akanteele Agandaa S, Kweku M, Agboli E, Takase M, Takramah W, Tarkang E, et al. Implementation and challenges of test, treat and track (T3) strategy for malaria case management in children under five years in the Bongo District, Ghana. Clin Res Trials. 2016;2(6):235-241. 
17. Baiden F, Malm K, Hodgson A, Chandramohan D, Webster J. Shifting from Presumptive to Test-based Management of Malaria - Technical Basis and Implications for Malaria Control in Ghana. Ghana Med J. 2014;48(2):112-122.

18. Kwarteng A, Asante KP, Abokyi L, Gyaase S, Febir LG, Mahama E, et al. Provider compliance to artemisinin-based combination therapy at primary health care facilities in the middle belt of Ghana. Malar $J$. 2015;14(1):1-11.
19. Kankpetinge C, Kweku M, Baiden F, Agboli E, Akapoeh D, Takramah W, et al. Clinicians ' Adherence to Implementation of Test, Treat and Track Strategy for Malaria Control among Children Underfive Years in Ho Municipality , Volta Region, Ghana. IJTDH. 2016;20(1):1-11.

20. World Health Organization. Surveillance for Malaria Control: An operational manual. 2012. http://www.who.int/malaria/publications/atoz/9789241503341/en/. 